\title{
Alcohol Consumption and Diabetes: A Case Control Study in a Rural Area of Kancheepuram District of Tamil Nadu.
}

\author{
Venkatachalam $\mathbf{J}^{1}$, Muthu Rajesh $\mathrm{E}^{2}$, Zile Singh ${ }^{3}$, Sathya $\mathrm{GR}^{4}$ \\ Assistant Professor, Department of Community Medicine, Pondicherry Institute of Medical Sciences, ${ }^{1,}$ \\ Post Graduate student, Pondicherry Institute of Medical Sciences, ${ }^{2,4}$ \\ Professor and HOD, Department of Community Medicine, Pondicherry Institute of Medical Sciences ${ }^{3}$
}

\begin{abstract}
Background: India was home to 62.4 million diabetics in the year 2011 and the incidence is on a continuous rise. It was projected that India will have the largest number of diabetics in 2025. So studying the risk factors for diabetes is much needed in India. Objectives: To assess the association between alcohol intake and diabetes mellitus in a study population and to assess the association between socio demographic profile and diabetes in a study population.

Methodology: A community based case control study to associate alcohol and diabetes was conducted in the rural area of Chunampet, Cheyyurtaluk of Kanchipuram district in Tamilnadu, which is under field practicing area, Rural Health Training Centre, Department of Community Medicine, Pondicherry Institute of Medical Sciences, Chunampet. Study participants: Adult population aged above 30 years of age. Sample size: Calculated using Epi info. 150 cases and 150 controls. Definition of cases: Known diabetics or persons with FBS $>126 \mathrm{mg} / \mathrm{dl}$ or RBS $>140 \mathrm{mg} / \mathrm{dl}$. Definition of controls: Persons who are not a known a case of Diabetes and with FBS $<126$ or RBS $<140$. Exclusion criteria: Critically ill persons, persons with other comorbidities. Questionnaire: A pre-designed and pre-tested questionnaire was used. Details regarding diabetes history, alcohol intake, physical activity were collected by house to house survey. Weight in kgs, height in cms were recorded. Blood sugar was estimated using Accu-chek glucometer. Results: The study was conducted with 150 Diabetics (Cases) and 150 Non-Diabetics (Controls). Among the 150 Diabetics (Cases), 124 were males and 26 females. And, among the 150 Non-Diabetics (Controls), 124 were males and 26 were females. Cases and controls are matched for sex and age ( \pm 5 years). Out of 85 subjects who consumed alcohol 63(74.11\%) were diabetics and out of 215 who were non drinkers $87(40.40 \%)$ were diabetics. A positive association between alcohol and diabetes was found (OR=4.21, 95\% CI 2.41-7.35) and it was statistically significant ( $p$ value 0.001 ).
\end{abstract}

\section{Introduction:}

Diabetes and alcohol consumption are two of the most dangerous public health problems our country faces. Due to improved curative services and vaccination coverage infectious diseases had been controlled to a great extent. So now there is a shift in disease pattern from communicable to non communicable diseases. Among this diabetes stands first which causes both health and economic burden to the patients as well as country. There were 62.4 million diabetics in India according to International Diabetes Federation in 2011 and the number of deaths due to diabetes in the year 2011 was $983,000^{[1]}$. India has the second largest number of diabetics next to China. The nationwide prevalence of diabetes is $9 \%$ and in southern cities it is as high as $20 \%$ [1]. The prevalence of alcohol consumption in India is around $21 \%$ among men and $2 \%$ among women ${ }^{[2]}$. Though this is less compared to western countries in a country with a population of 1.2 billion the number of people with alcohol consumption can be calculated. A recent survey had found out that the percent of drinking population under the age of 21 had gone from $2 \%$ to $14 \%$ and the average age of initiation of drinking had dropped from 19 to 13 years in the last twenty years ${ }^{[3] .}$ Alcohol affects pancreas directly besides liver, GIT and CNS. Alcohol influences glucose metabolism in several ways in diabetic patients as well as in non-diabetic patients. Taken with food alcohol is the preferred fuel and causes higher blood glucose levels leading to insulin response. Since alcohol inhibits both gluconeogenesis and glycogenolysis, its acute intake without food may provoke hypoglycemia, especially in cases of depleted glycogen stores and in combination with sulphonylurea. Though there are some positive effects of alcohol in preventing atherosclerosis when consumed in large quantities this effect is nullified. Thus both alcohol and diabetes are major public health problems posing a major threat to our country's economy and productivity.

Most of the studies conducted to find the association between alcohol intake and Diabetes were done on hospital basis. As alcohol intake is a modifiable risk factor community based studies should be done to find the association between alcohol and Diabetes to create public awareness.

OBJECTIVES: 
1. To assess the association between alcohol consumption and diabetes mellitus among a rural population of Kancheepuram district of Tamil Nadu.

2. To assess the association between socio demographic factors and diabetes in the study population.

\section{Methodology:}

Study Setting: A community based age ( \pm 5 years) and sex matched case control study to associate alcohol and diabetes was conducted in the rural area of Chunampet, Cheyyur Thaluk of Kanchipuram district in Tamil Nadu, which is under field practice area, Rural Health Training Centre under Department of Community Medicine, Pondicherry Institute of Medical Sciences. Study period: September 2012 to October 2012. Study participants: Adult population above 30 years of age. Sample size: Based on previous studies sample size was calculated using Epi info software and was found to be 123 for $95 \%$ CI. We selected 150 cases and 150 controls. Definition of cases: Known diabetics and persons with FBS $>126 \mathrm{mg} / \mathrm{dl}$ or RBS $>140 \mathrm{mg} / \mathrm{dl}$. Definition of controls: Persons who are not a known a case of Diabetes and with FBS $<126 \mathrm{mg} / \mathrm{dl}$ or RBS $<140 \mathrm{mg} / \mathrm{dl}$. Exclusion criteria: Critically ill person and Persons with other co morbidities. Sampling: All eligible participants were selected by doing house to house survey. 3 house visits were made in case eligible subjects were not available on first visit. Subjects who refused and those who were non available despite 3 visits were excluded. Questionnaire: A pre-designed and pre-tested questionnaire was used. All subjects were interviewed in local language. Information about socio demographic profile, diabetic status and alcohol consumption habits was collected. Weight in $\mathrm{kgs}$ and height in $\mathrm{cms}$ were measured. Blood sugar was estimated using Accu-chek glucometer which uses dependent glucose oxidoreductase mediator reaction. Diabetes was diagnosed if FBS $>126 \mathrm{mg} / \mathrm{dl}$ or PPBS $>200 \mathrm{mg} / \mathrm{dl}$. All interviews and tests were conducted by interns and post graduates under the supervision of faculties. Ethical Considerations: Informed verbal consent was obtained from the study participants before obtaining the data. Provision for referral and service were made for participants who were diagnosed newly as diabetics. Data Analysis and Statistical Methods:. The data were entered in the MS excel and analysis was done using SPSS 16. Proportions and Odd's ratio were calculated, Chisquare test and univariate analysis was done. Statistical significance were referred to as $\mathrm{p}<0.05$.

\section{Results:}

Out of the 300 study subjects $248(82.7 \%)$ were men and 52(17.3\%) were women. Out of these subjects cases and controls are equally distributed in both sexes. Among these $155(51.66 \%)$ participants were in the age group 41-50, 106(35.33\%) were doing semi skilled occupation and $82(27.33 \%)$ were illiterate. The data from our study shows that professionals $(\mathrm{OR}=9)$ and graduates $(\mathrm{OR}=5.79)$ have higher odd's to develop diabetes when compared to other occupational and educational groups respectively. Interestingly out of 52 middle school subjects cases and controls are equal in number and also prevalence of diabetes was less among higher secondary education group when compared to other groups.

Table 1: Association between Socio Demographic Profile versus Diabetes

\begin{tabular}{|cccccc|}
\hline Gender & Cases & Controls & Total & Odd ratio & pValue \\
Males & 124 & 124 & $248(82.7 \%)$ & $*$ & 1 \\
Females & 26 & 26 & $52(17.3 \%)$ & & \\
Age & & & & & \\
$30-40$ & $30(48.4 \%)$ & $32(51.6 \%)$ & $62(100 \%)$ & & \\
$41-50$ & $79(51 \%)$ & $76(49 \%)$ & $155(100 \%)$ & $*$ & 0.9 \\
$51-60$ & $35(50.7 \%)$ & $34(49.3 \%)$ & $69(100 \%)$ & & \\
$61-70$ & $6(42.9 \%)$ & $8(57.1 \%)$ & $14(100 \%)$ & & \\
Occupation & & & & & \\
Unemployed & $20(32.8 \%)$ & $41(67.2 \%)$ & $61(100 \%)$ & Reference & \\
Unskilled & $30(39 \%)$ & $47(61 \%)$ & $77(100 \%)$ & 1.31 & \\
Semiskilled & $66(62.3 \%)$ & $40(37.7 \%)$ & $106(100 \%)$ & 2.36 & 0.001 \\
Skilled & $27(57.4 \%)$ & $20(42.6 \%)$ & $47(100 \%)$ & 2.77 & \\
Professional & $7(87.5 \%)$ & $2(22.2 \%)$ & $9.0(100 \%)$ & 7.17 & \\
Education & & & & & \\
Higher secondary & $14(34.1 \%)$ & $27(65.9 \%)$ & $41(100 \%)$ & Reference & \\
Illiterate & $36(46.1 \%)$ & $46(56.1 \%)$ & $82(100 \%)$ & 1.51 & \\
Primary & $21(48.8 \%)$ & $22(51.2 \%)$ & $43(100 \%)$ & 1.84 & \\
Middle school & $26(50 \%)$ & $26(50 \%)$ & $52(100 \%)$ & 1.93 & 0.01 \\
High school & $44(62.9 \%)$ & $26(37.1 \%)$ & $70(100 \%)$ & 3.26 & \\
Graduates & $9(75 \%)$ & $3(25 \%)$ & $12(100 \%)$ & 5.79 & \\
\hline
\end{tabular}


Among these 85 subjects were drinkers out of which $63(74.11 \%)$ were diabetics. Among 85 alcohol consumers 44 consume $(51.7 \%)$ weekly once, $57(67.07 \%)$ consume brandy and $45(52.94 \%)$ consume $90-180 \mathrm{ml}$ per episode. From this we can conclude that alcohol is an independent risk factor for diabetes $(\mathrm{OR}=4.21, \mathrm{p}$ value $<0.01)$.

Table 1: Association between alcohol habits versus Diabetes

\begin{tabular}{|l|c|c|c|c|c|}
\hline Characteristics & Cases & Controls & Total & $\begin{array}{c}\text { Odd's } \\
\text { ratio }\end{array}$ & p value \\
Non-drinkers & $87(40.4 \%)$ & $128(59.6 \%)$ & 215 & & \\
$\quad$ Drinkers & $63(74.1 \%)$ & $22(25.9 \%)$ & 85 & 4.21 & 0.001 \\
Frequency & & & & & \\
Non-drinkers & $87(40.4 \%)$ & $128(59.6 \%)$ & 215 & Reference & \\
Daily & $13(76.4 \%)$ & $4(23.6 \%)$ & 17 & 4.78 & \\
Weekly 3-4time & $17(70.8 \%)$ & $7(29.2 \%)$ & 24 & 3.57 & 0.001 \\
Weekly once & $30(68.1 \%)$ & $14(31.9 \%)$ & 44 & 3.15 & \\
Type & & & & & \\
Non-drinkers & $87(40.4 \%)$ & $128(59.6 \%)$ & 215 & Reference & \\
Brandy & $44(77.1 \%)$ & $13(22.9 \%)$ & 57 & 4.98 & 0.001 \\
Rum & $8(72.7 \%)$ & $3(27.3 \%)$ & 11 & 3.92 & \\
Whisky & $11(64.7 \%)$ & $6(35.3 \%)$ & 17 & 2.7 & \\
Amount & & & & & \\
Non-drinkers & $87(40.4 \%)$ & $128(59.6 \%)$ & 215 & Reference & \multirow{2}{*}{0.001} \\
90ml & $9(64.2 \%)$ & $5(35.8 \%)$ & 14 & 2.65 & \\
90-180ml & $30(66.6 \%)$ & $15(33.4 \%)$ & 45 & 2.94 & \\
>180ml & $24(92.3 \%)$ & $2(7.7 \%)$ & 26 & 17.66 & \\
& & & & & \\
\hline
\end{tabular}

\section{Discussion:}

From our study we found that among socio demographic factors occupation and educational level may be associated with diabetes. As professional and highly educated persons have higher risk for diabetes when compared to other groups. This may be due their sedentary life style. This pattern is entirely different from developed countries where the prevalence is more among lower education and occupational groups ${ }^{[4,5,6]}$. But studies in India reveal those highly educated and higher socio economic groups are at higher risk ${ }^{[7,8]}$. So this implies public awareness regarding diabetes risk factors is needed among all socio economic and educational groups.

We also found that alcohol is a separate risk factor for diabetes $(\mathrm{OR}=4.21, \mathrm{p}$ value $<0.001)$. Also this positive association was found to be dose dependent, those who consume daily are at more risk $(\mathrm{OR}=4.78, \mathrm{p}$ value $<0.001)$ and those who consume more than $180 \mathrm{ml}$ are at more risk $(\mathrm{OR}=17.66$, $\mathrm{p}$ value $<0.001)$. Literature shows variable results for alcohol and diabetes, some studies report no association ${ }^{[9,10,11]}$. But a positive association and dose response relations were found in some studies ${ }^{[12,13,14,15]}$. Our study also shows that brandy is the preferred drink compared to other alcoholic beverages and also those who consume brandy are at higher risk to develop diabetes compared to other drinks $(\mathrm{OR}=4.78, \mathrm{p}$ value $<0.001)$. But this finding may be due to high proportion of brandy consumers among study subjects. From this we can conclude that alcohol is a risk factor for diabetes mellitus.

All these results were obtained after adjusting for age and sex and found to be statistically significant. Since there is controversy regarding alcohol as risk for diabetes further studies should be done to establish the relation. Though our study focuses on diabetes alcohol causes many other major public health problems and issues like accidents, increased crime rates, pre mature deaths etc. So this is time for our administrators to think about prohibition and to take strict legislative measures to control alcoholism.

\section{References:}

[1] Priya Shetty. India's Diabetic time bomb. Nature 2012; 485: 14-15

[2] Raekha Prasad. Alcohol on the rise in India. Lancet medical journal vol 373 Jan 2009

[3] Pattern of drinking in Kerala, Drugs information centre India (NGO), available from URL: http:// www.adicindia.org/publications.html

[4] Siobhan C Maty, Susan A Everson-Rose, Mary N Haan, Trivellore E Raghunathan and George A Kaplan. Education, income, occupation, and the 34-year incidence (1965-99) of Type 2 diabetes in the Alameda County Study Int J Epidemiol. 2005 December ; 34(6): 1274-1281.

[5] Stringhini S, Tabak A , Akbaraly T, Sabia S, Shipley M, Marmot M et al. Contribution of modifiable risk factors to social inequalities in type 2 diabetes: prospective Whitehall II cohort study. BMJ 2012;345:e5452 
[6] Maty S, James S, Kaplan G. Life-Course Socioeconomic Position and Incidence of Diabetes Mellitus Among Blacks and Whites: The Alameda County Study, 1965-1999 American Journal of Public Health 2010; 100: 137-145.

[7] Agarwal S, Ebrahim S. Prevalence and risk factors for self-reported diabetes among adult men and women in India: findings from a national cross-sectional survey Public Health Nutrition: 15(6), 1065-1077.

[8] Kinra S, Lyngdoh T, Prabaharan D, Reddy K, Ramakrishnan L, Gupta R et al. Socio demographic patterning of non-communicable disease risk factors in rural India: a cross sectional study BMJ 2010;341:c4974.

[9] Prabhakaran D, Chaturvedi V, Ramakrishnan L et al. Risk factors related to the development of diabetes in men working in a north Indian industry. National Medical Journal of India. 2005;20(1):4-10.

[10] Dutt D, Roy G, Chatterjee P. Risk Factor Assessment for Type II Diabetes Mellitus in a Tertiary Hospital in Kolkata. Indian Journal of Community Medicine. 2004;29(4):169-170.

[11] Majgi SM, Soudarssanane BM, Roy G, Das AK. Risk Factors of Diabetes Mellitus in Rural Puducherry. Online J Health Allied Scs. 2012;11(1):4

[12] Van de Wiel A : Diabetes mellitus and alcohol. Diabetes/Metabolism Research and Reviews. 2004; $20: 263-67$.

[13] Ming Wei, Larry W. Gibbons, Tedd L. Mitchell, James B. Kampert, Steven N. Blair: Alcohol intake and incidence of type 2 Diabetes in men. Diabetes Care 23:1 8-22, 2000.

[14] Pietraszek A, Gregersen S, Hermansen K Alcohol and type 2 diabetes. A review. Nutrition, Metabolism and Cardiovascular diseases. 2010; 20(5): 366-75.

[15] Troy L. Holbrook, Elizabeth Barrett-Connor And Deborah L. Wingard :A prospective population-based study of alcohol use and noninsulin-dependent diabetes mellitus. American Journal of Epidemiology. 1990; 132(5):902-09.

\section{Contributions:-}

Venkatachalam J: Conception and design of the study; planning and conducting the study; analysis and interpretation of data; and drafting the paper.

Muthu Rajesh.E: Design of the study, drafting the paper and revising the draft critically for substantial intellectual content.

Zile Singh: Design of the study; planning and coordinating the study;

Sathya GR:- Analysis and interpretation of data; drafting the paper and revising the draft critically for substantial intellectual content.

\section{Conflict of Interest:- None. Role of Funding Source:- Pondicherry Institute of Medical Sciences}

Acknowledgements:-

The authors would like to thank Dr.P.Stalin and Dr. Jayaramachandiran for providing guidance for this study. The authors want to extend thanks to interns for helping in data collection and data entry. Also extend thanks to Dr. Arun, Dr .Sivaraj RMOs, RHTC Chunampet for their cooperation. 